\title{
Well That Was Unexpected: Effect of Intimacy and Commitment on Responses to an Interpersonal Expectancy Violation
}

\author{
Norman Wong \\ Correspondence: Norman Wong, University of Oklahoma, USA. \\ Received: August 30, 2018 \\ doi:10.11114/smc.v6i2.3586 \\ Accepted: October 14, 2018 \\ Online Published: October 16, 2018 \\ URL: https://doi.org/10.11114/smc.v6i2.3586
}

\begin{abstract}
This investigation explored the effect an individual's level of relational commitment and intimacy has on his or her perceptions of and responses to a positive or negative expectancy violation performed by their dating partner. One hundred-ninety undergraduates were randomly assigned to read 1 of 4 scenarios depicting a situation involving their dating partner committing either a positive/negative expectancy violation. Participants were asked to assess the situation in terms of the nature of the expectancy violation (positive/negative), violation severity, and level of unexpectedness. Moreover, they were asked the extent to which they were willing to talk about the situation with the other person. Results found that perceived intensity of violations varied depending on both the nature of the expectancy violation and commitment/intimacy level. Highly committed/intimate respondents reported greater willingness to discuss negative expectancy violations with the other person than less committed/intimate respondents, but reported lower likelihood in using negativity as their strategy. Less committed/intimate respondents reported greater willingness to discuss positive expectancy violations compared to their highly committed/intimate counterparts.
\end{abstract}

Keywords: expectancy violations theory, intimacy, commitment

\section{Introduction}

Intimacy and commitment are two important constructs that characterize and discriminate romantic relationships from other relational types. In the context of a dating relationship, these constructs help to delineate casual dating and exclusive dating relationships, as well as provide a lens through which relational behaviors are interpreted. While relational disclosure, calendar time, and general day-to-day interactions all contribute to the level of intimacy/commitment perceived within a relationship, this perception in turn likely affects how relational partners will perceive and respond to different relational situations.

The current paper examines how the commitment and intimacy perceived by individuals in a dating relationship affects their perceptions of and responses to positive and negative expectancy violations enacted by their dating partner. Specifically, it is expected that depending on the level of commitment/intimacy reported, individuals will perceive the enactment of a positive/negative behavior by their dating partner differently in terms of the behavior's importance and expectedness. Moreover, reactions to the behavior are expected to differ as well in terms of the individual's willingness to directly discuss the situation with the dating partner, and level of negativity in their response to the behavior. Hence, an appropriate theoretical framework to use for this study is expectancy violations theory (EVT). The following section provides a brief overview of the theory.

\subsection{Expectancy Violations Theory}

Generally, expectancies are defined as "cognitive, affective, and conative components and include judgments of what behaviors are possible, feasible, appropriate, and typical for a particular setting, purpose, or set of participants" (Burgoon \& Hale, 1988, p. 60). They serve as a guide helping individuals to frame interpersonal interactions and subsequently affects their information processing, perceptions, and relational behaviors (Burgoon, 1993; Burgoon \& Hale, 1988). As discussed within EVT, individuals in relationships are said to have preconceived expectations of how their relational partners will communicate in interactions, and that these expectancies may either be confirmed or violated when engaging in interactions with them (Burgoon \& Hale, 1988).

A relational expectancy confirmation is defined as a situation where a person's actual behavior is consistent with what is expected given the nature of the relationship (Burgoon \& Hale, 1988). Such confirmations can either be positively or negatively valenced (i.e., a person may expect the other individual to interact in a positive/negative manner). In both 
cases, no further interpretation is necessary given that the enacted behavior conforms to what is expected in the relationship.

Conversely, a relational expectancy violation occurs when a person's enacted behavior deviates from what is expected given the relationship between the individuals (Afifi \& Metts, 1998). An expectancy violation triggers cognitive arousal, which in turn initiates an interpretation and evaluation process that helps an individual cope with the unexpected behavior (Afifi \& Metts, 1998). Additionally, after an expectancy violation takes place, individuals are said to focus their attention to the relational meaning of messages communicated by the other person (Burgoon \& Hale, 1988; LePoire \& Burgoon, 1994).

In interpreting expectancy violations, individuals are primarily concerned with determining the nature of the expectancy violation (i.e., positive or negative), a decision greatly influenced by the reward value of the person committing the violation. According to EVT, the more rewarding the violator is, the less likely the expectancy violation will be judged as negative in nature (Burgoon, 1993; Burgoon \& Hale, 1988). Expanding on this interpretation process, Afifi and Metts (1998) argued three elements of an expectancy violation are considered: (a) violation valence, the degree to which the unexpected behavior is seen as positive or negative in nature, (b) violation expectedness, reflecting the degree the enacted behavior was unexpected, falling along a continuum from "not at all unexpected" to "highly unexpected," and (c) violation importance, defined as the extent to which the behavior is perceived to have significant relational impact for the person. The greater the importance of an expectancy violation, the more intense it is perceived to be.

In judging these three aspects of an expectancy violation, the outcome of this process may be affected by a wide variety of factors (e.g., reward valence of the violator). After evaluating the expectancy violation, individuals generally respond in 1 of 3 ways (i.e., reciprocation, compensation, or non-accommodation). In most cases, positive violations are reciprocated whereas compensation or non-accommodation likely follows negative violations.

Despite the fact that expectancy violations have been studied in various relational contexts, such as within cross-sex friendships and romantic relationships (e.g., Afifi \& Faulkner, 2000; Afifi \& Metts, 1998), there is a gap in our understanding of the effects different relational characteristics have on how people interpret and respond to relational expectancy violations.

Moreover, most of the research on expectancy violations tends to focus on examining only negative expectancy violations (e.g., Bevan, 2003; Roloff \& Cloven, 1994). Lacking is research on positive expectancy violations. In the present study, we address both these gaps by taking a closer look at how two relational characteristics (i.e., intimacy and commitment) impact the way people interpret and react to both positive and negative expectancy violations. A brief review of the two relational characteristics is provided in the next section.

\subsection{Intimacy}

Intimacy is a construct that has been widely studied within the personal relationships literature (Pilkington \& Woods, 1999). As is the case with most communicative constructs, individuals vary on the degree to which they desire intimacy and the means they employ to achieve, sustain, and manage increased levels of it (Honeycutt, Cantrill, Kelly, and Lambkin, 1998). A variety of definitions exists for what constitutes intimacy. Specifically, intimacy can be defined in terms of as a quality of persons, interactions, or relationships.

As a quality of persons, intimacy is defined as a dispositional characteristic upon which individual differences exists regarding the need or desire for intimacy. Specifically, intimacy is viewed as a motivational force behind people's behaviors. For instance, Solomon (1997) characterized intimacy as a drive for attaining "positive social outcomes" (p. 100) and may occur in any type of relationship, be it friendship or romantic. Intimacy is said to be the goal of personal relationships and reflects the psychological, emotional, and social statuses of individuals in conjunction with each other (Solomon, 1997).

As a quality of interactions, intimacy is defined by the specific behaviors enacted within an interpersonal interaction. Specifically, the level of intimacy between two individuals are reflected by a variety of nonverbal (e.g., changes in interpersonal distances, level of eye contact, use of touch) and verbal behaviors (e.g., depth of self-disclosures). Lastly, as a quality of relationships, intimacy is defined as a specific type of relationship between individuals. Prager (1995) defines intimate relationships as ones in which intimate interactions occur on a regular basis. While intimate interactions consist of both intimate behaviors and experiences that occur over a specific period of time, intimate relationships are formed by the "by-products" of repeated intimate interactions that become stable characteristics of the relationship, and contribute to the judgment of whether or not the relationship is intimate (Prager, 1995). Specifically, intimate relationships are defined as those that are characterized by sustained affection, mutual trust, and partner cohesiveness (Prager, 1995). These three features of an intimate relationship are developed as a result of repeated intimate interactions between individuals, and are used as criteria for deciding whether a relationship is intimate or non-intimate in nature. 
In measuring intimacy, the debate focuses on whether this construct should be assessed qualitatively or quantitatively. Prior research has tended to utilize a qualitative approach in examining intimacy. Specifically, the focus is on identifying different types of communicative behaviors that signal various levels of intimacy (e.g., Falk \& Wagner, 2001; Guerrero, 1996; Seki, Matsumoto, \& Imahori, 2002) or that fluctuates in relationships to the degree of intimacy perceived, rather than attempting to quantify intimacy as a measurable state. The present study will treat intimacy as a quantifiable construct, measuring it along a continuum.

In studies that have quantified intimacy as a measurable state, it has generally been found that a curvilinear relationship exists between intimacy and message explicitness (Emmers \& Dindia, 1995; Solomon, 1997). Specifically, Solomon (1997) found a U-shaped relationship between intimacy and explicitness of requests. Explicitness of request was found to be low at moderate levels, but high when intimacy between partners were either high/low (Solomon, 1997). One reason for this finding may be that less intimate partners may feel compelled to be more explicit because relational expectations are less likely to be well-defined. Among highly intimate partners, increased explicitness may exist because of increased relational comfort levels. However, moderately intimate partners may be more reluctant to make explicit requests for fear of offending the other person or damaging the transient relationship.

\subsection{Commitment}

A related construct to intimacy that has also garnered a great deal of research attention is commitment. In the past few decades, many relational scholars have exerted great efforts to understand why some personal relationships grow stronger with time, while others wither and die. Relational commitment is a multifaceted and complex process (Fehr, 1999). On the simplest level, commitment is used to describe the likelihood a relationship will persist over time (Arriaga \& Agnew, 2001). Many scholars have also conceptualized commitment as the degree to which attracting forces overwhelm repelling forces in a relationship (e.g., Adams \& Jones, 1997; Arriaga \& Agnew, 2001; Rusbult \& Buunk, 1993; Rusbult, 1983).

In this study, relational commitment is defined as a subjective state in which a person adopts a long-term orientation toward his or her relationship, characterized by a strong desire to maintain it, and sacrifice for it regardless of the condition of the relationship (Rusbult \& Buunk, 1993). Theoretically, this definition is consistent with how commitment is described within the investment model (i.e., Rusbult, 1983).which suggests a person's level of relational commitment is affected by three factors: (a) satisfaction, (b) quality of alternatives, and (c) level of investments.

According to the model, highly committed individuals are those who are highly satisfied, perceive few attractive alternatives, and have made large investment in their relationships (Rusbult, 1983). Numerous studies provide support for the investment model, using both cross-sectional and longitudinal data among college-age daters (Rusbult, 1983) and married and cohabitating couples (Rusbult, Johnson, \& Morrow, 1986; Impett, Beals, \& Peplau, 2001).

Both intimacy and commitment are highly related constructs and it is expected that they will have similar effects on how individuals will perceive and respond to a positively/negatively valenced situation involving their dating partners. The reason for including both constructs is to determine the effects of the relationship itself (i.e., the fact that it is a highly intimate or less intimate relationship), as well as the effects of an individual's desire to maintain the relationship (i.e., high or low desire) on their perceptions and behaviors following a positive/negative relational event. The next section lays out the specific predictions of this study.

\subsection{Intimacy, Commitment, and Expectancy Violations}

Based on previous research, it is argued that an individual's perception of and response to positive and negative expectancy violations in his or her relationship will differ depending on the person's level of relational commitment or perceived intimacy in the relationship. We will consider situations involving positive and negative expectancy violations separately. First, let us examine a situation involving a positive expectancy violation. This occurs when a partner enacts a behavior that is judged to be more positive than expected. For example, this might entail the performance of unanticipated pro-relationship behaviors by a partner including: derogation of one's own relational alternatives, making a personal sacrifice for the partner, and engaging in accommodation to meet the partner's needs. Generally speaking, a pro-relationship behavior can be thought of as any action taken to enhance relationship quality.

It has been argued that the level of commitment or intimacy perceived within a relationship reliably predicts to what extent pro-relationship behaviors are enacted (Rusbult, Drigotas, \& Verette, 1994). Specifically, the greater the commitment/intimacy perceived, the more likely pro-relationship behaviors are enacted. Several reasons are offered for why this is the case. First, highly committed and/or intimate partners are dependent and often need their relationships. The more a person stands to lose from ending the relationship, the greater the effort exerted to sustain the relationship (Rusbult, 1983). Next, commitment involves adopting a long-term perspective in viewing the relationship (Rusbult, \& Buunk, 1993). Such involvement typically requires the enactment of pro-relationship behavior to maintain them. Finally, 
commitment and/or intimacy are likely to induce a communal orientation, characterized as the tendency to unconditionally accommodate to the needs of the partner (Wieselquist, Rusbult, Foster, \& Agnew, 1999). Such an orientation may also motivate the enactment of pro-relationship behavior, as well, in the relationship.

Hence, if a partner commits a positive expectancy violation (i.e., unexpected pro-relationship behavior), this may signal the partner is more invested in the relationship than expected, or is seeking to create greater intimacy than anticipated. In such a case, highly committed individuals or those in highly intimate relationships are not likely not to perceive such behavior as an expectancy "violation," but rather as a positive expectancy confirmation given the nature of their relationship. As such, reciprocation is likely to occur.

Similarly, given the positive nature of pro-relationship behaviors, it is expected that those who are not highly committed to their partners, or are in a less intimate relationship will also enact reciprocation as a response to the enacted behavior. However, unlike their highly committed/intimate counterparts, these individuals will likely view such behaviors as a positive expectancy violation given the nature of their relationship. And so, despite their similarities in how they will likely respond to the situation (i.e., reciprocation), there will be differences in the degree to which the pro-relationship behavior is judged as expected or unexpected.

Moreover, there may also be differences in terms of how important individuals will perceive the positive behavior to be for the relationship. In the case of highly committed/intimate individuals, given that pro-relationship behaviors are expected, the enactment of such behaviors will likely raise little arousal, and be perceived as having a low level of intensity as a behavior.

On the other hand, for those less committed/intimate, pro-relationship behaviors are likely viewed as positive expectancy violations, and so, it will likely raise greater arousal, and be perceived as having a higher level of intensity as a behavior than if the behavior was perceived as a positive expectancy confirmation. Thus, the following hypotheses are posited:

H1: Level of perceived commitment/intimacy will be negatively related to the level of unexpectedness of behavior in the positive behavior conditions.

H2: Level of perceived commitment/intimacy will be negatively related to the level of importance of behavior within the positive behavior conditions.

As for how both groups will respond to the enactment of positive behaviors in their relationship (whether expected or unexpected), it is anticipated that both groups would respond in a positive manner to the situation. However, compared with highly committed/intimate individuals, those less committed to or intimate with their partners should be more likely to explicitly discuss the behavior with the other person. For these individuals, a positive expectancy violation will likely trigger arousal, which in turn would motivate them to explicitly discuss the situation with the other person in order to clarify the nature of their relationship. This is particularly true if the individual is happy maintaining low levels of commitment/intimacy with the other person, whereby positive violations will likely trigger great levels of arousal.

Conversely, those highly committed to or intimate with their partners are likely to be less explicit in discussing the situation with the other person. For these individuals, because the enactment of positive behaviors are expected and constitute positive expectancy confirmations, they are less likely to experience arousal, and thus have less motivation to talk about the situation with the other person. And so, the following hypothesis is posited:

H3: Level of perceived commitment/intimacy will be negatively related to the level of explicitness in response reported within the positive behavior conditions.

Now, let us consider a situation involving a negative expectancy violation. This occurs when a partner engages in behaviors perceived to be more negative than expected (e.g., acts of betrayal such as disclosing a secret to others or criticizing the partner in public). When this occurs, due to the fact that such behaviors are hurtful to the partner, it is likely to be perceived as an expectancy violation by both individuals in highly committed/intimate relationships as well as those in less committed/intimate relationships.

However, highly committed or intimate individuals will likely judge the expectancy violation more intensely and as more unexpected than less committed and intimate individuals. The reason is for those in less committed/intimate relationships, they are not as invested in the relationship, and so, acts of betrayal or wrongdoing by a partner likely elicits less hurt compared to those in highly committed/intimate relationships, where the hurt is more intense. Moreover, the enactment of a transgression by a partner within a highly committed/intimate relationship will be more of a shock (i.e., violation of expectations) than by a person within a less committed/intimate relationship where relational expectations may be more uncertain. And so, the following hypotheses are posited:

H4: Level of perceived commitment/intimacy will be positively related to the level of importance 
perceived for negative expectancy violations.

H5: Level of perceived commitment/intimacy will be positively related to the level of unexpectedness perceived for negative expectancy violations.

As for how both groups will likely respond to negative violations, highly committed/intimate individuals will likely be more direct in talking to their partners about the negative behavior than less committed/intimate individuals (e.g., Rusbult et al. 1986). Directly confronting one's partner about his or her negative behaviors may be viewed as a way of maintaining a strong relationship by taking care of the issue before it worsens (Roloff \& Solomon, 2002). In their study, Rusbult et al. (1986) found relational investment and satisfaction are both positively related to talking to partners about their irritating behaviors. On the other hand, there is greater risk involved for those less committed to or intimate with their partners to directly confront them about their negative behaviors for fear of negative repercussions. It has been argued that for those who are not very committed to or intimate in their relationships, the potential costs of confrontation often outweigh the rewards (Roloff \& Solomon, 2002). Specifically, for these individuals, they fail to see the upside of exposing oneself to potentially negative reactions that can result from confronting the partner about their negative behaviors. As such, these individuals are motivated to engage in either avoidance or enact passive behaviors to deal with the situation (e.g., passive aggressiveness). Thus, the following hypothesis is posited:

H6: Level of perceived commitment/intimacy will be positively related to the level of explicitness reported in discussing negative expectancy violations.

However, although highly committed/intimate individuals may be more willing to bring up the negative behavior with their partner than those who are less committed to or intimate with their partner, there is also an expectancy for them to confront the other person in a less negative manner. Specifically, past research demonstrates relational distress is greater when hurtful messages come from intimate compared to non-intimate partners (Vangelisti \& Crumley, 1998). Because highly committed/intimate individuals are more likely to care about not hurting or causing distress to their partner than those less committed/intimate, they are expected to respond with less negativity to the violation.

H7: Level of perceived commitment/intimacy will be negatively related to the level of negativity reported in response to negative expectancy violations.

\section{Methods}

\subsection{Participants}

One-hundred ninety undergraduate communication students ( 85 males, 105 females) at a large southern university were recruited to take part in this study. Participants ranged in age from 17 to 25 with a median age of 21 years $(S D=3.03)$. The sample was predominantly White, with approximately $55.3 \%$ of the participants reporting on a current dating relationship, and $44.2 \%$ reporting on their most recent dating relationship. The average length of participants in a current dating relationship was 20.84 months $(S D=33.67)$. The average length of participants in a recent dating relationship was 14.33 months $(S D=18.95)$.

\subsection{Procedures}

Participants were asked to read over the informed consent form and after giving consent, were handed a survey packet to complete. First, they responded to a number of demographic questions and a few items about their current or most recent dating relationship. Second, they were instructed to select and think about either their current dating relationship (if they had one), or their most recent dating relationship in answering questions about perceived intimacy and commitment. Third, participants read 1 of 4 randomly assigned expectancy violation scenarios describing either a positive or negative expectancy violation situation, and asked to imagine that the person committing the expectancy violation is their current or most recent dating partner. Fourth, they were asked to judge the situation and respond to the events described in the scenario. Finally, once participants completed the survey, they were debriefed about the nature of the study and thanked for their participation.

\subsection{Scenarios and Pilot Testing}

Participants were randomly assigned consider 1 of 4 scenarios describing a situation where the participants' current or most recent dating partner engages in a relational expectancy violation. Two different scenarios depicting a positive expectancy violation situation and two depicting a negative expectancy violation situation were used in this study. These scenarios were adapted from a study by Afifi, Falato, and Weiner (2001) and Samp (2000). A pilot test was conducted with 85 undergraduates who rated the different scenarios on: (a) typicality, (b) severity of expectancy violation, (c) realism, (d) level of unexpectedness, (e) degree of positive expectancy violation, and (f) degree of negative expectancy violation. Based on the pilot data, four scenarios (2 positive and 2 negative) were selected for this study. For a description of the scenarios used, labeled "The Secret" and "The Party," please see Appendix A. 


\subsection{Measurement}

\subsubsection{Intimacy}

Participants' level of perceived intimacy in their current or most recent dating relationship was measured using a modified version of Miller and Lefcourt's (1982) Social Intimacy Scale. Sample items include "how often do you confide very personal information to your partner? And "how important is it to you that your partner understands your feelings?" Participants responded to these items on a 7-point Likert-type scale (i.e., $1=$ strongly disagree, $7=$ strongly agree). The scale yielded an alpha reliability of .94 . Higher scores on this scale represent higher levels of intimacy perceived in the relationship.

\subsubsection{Commitment}

Participants' level of commitment to their current or most recent dating relationship was measured using a modified version of Rusbult's (1980) investment scale. Sample items include "I am committed to maintaining my relationship with my partner" and "I am very involved in our relationship." Respondents were asked the extent to which they agreed with the statements (i.e., $1=$ strongly disagree, $7=$ strongly agree). The scale yielded an alpha reliability of .96 , with $\mathrm{H}=$ higher scores reflecting greater levels of relationship commitment.

\subsubsection{Unexpectedness of Behavior}

Based on Afifi and Mett's (1998) study, several items were constructed to measure the degree to which participants perceived the behaviors enacted in the different scenarios as unexpected. Sample items include, "this situation would be unexpected" and "this situation is likely to occur in dating relationships." Participants were asked to what extent they agreed with the statement (i.e., $1=$ strongly disagree, $7=$ strongly agree). The scale yielded an alpha reliability of .85 , with higher scores reflecting greater unexpectedness of behavior (i.e., more of an expectancy violation).

\subsubsection{Importance of Behavior}

A number of modified items were developed from Afifi and Mett's (1998) study to measure the degree participants perceived the expectancy confirming or violating behavior as important to their relationship. Sample items include, "I would take this situation very seriously" and "I would characterize this situation as severe." Respondents answered the questions using a 7-point Likert-type scale (i.e., $1=$ strongly disagree, $7=$ strongly agree). The scale had an alpha reliability of .90 with higher scores reflecting greater levels of importance perceived toward the behavior.

\subsubsection{Valence of Behavior}

A number of items were constructed based on Afifi and Mett's (1998) study to measure participants' judgments regarding the nature of the behavior depicted in the scenario as either positive or negative. Sample items include, "I would view this situation positively" and "I would be very disappointed if this situation occurred." Participants were asked how much they agreed with these statements using a 7-point Likert-type scale (i.e., $1=$ strongly disagree, $7=$ strongly agree). The scale yielded an alpha reliability of .83, with higher scores indicating more positive feelings toward the behavior.

\subsubsection{Negativity in Response to Behavior}

A number of items, adapted from Samp and Solomon (1998) were used to measure participants' likelihood to respond negatively to their partner following the expectancy confirming/violating behavior. Sample items include, "I would insult my partner" and "I would say or do something to spite my partner" rated on a 7-point scale (i.e., 1 = strongly disagree, $7=$ strongly agree). The scale has an alpha reliability of .85 , with higher scores reflecting greater negativity in response.

\subsubsection{Explicitness in Response to Behavior}

Adapted from Samp and Solomon (1998), a number of items were created to measure participants' likelihood to explicitly talk to their partner following the expectancy confirming/violating behavior. Sample items include, "I would explicitly address the situation with my partner" and "I would explicitly question my partner's intentions" rated on a 7-point scale (i.e., $1=$ strongly disagree, $7=$ strongly agree). The scale yielded an alpha reliability of .81 , with higher scores reflecting greater explicitness in response.

\section{Results}

\subsection{Manipulation Check}

A multivariate analysis of variance (MANOVA) was performed on the data set, with unexpectedness of behavior, importance of behavior, and valence of behavior as the dependent variables, and scenario type as the independent variable. Contrasts were constructed comparing between scenario conditions on the three dependent variables. Results indicate significant main effects for unexpectedness of behavior, $F(3,186)=29.25, p<.001, \eta^{2}=.32$, importance of 
behavior, $F(3,186)=18.58, p<.001, \eta^{2}=.50$, and valence of behavior, $F(3,186)=78.19, p<.001, \eta^{2}=.56$. Looking at the estimated marginal means, the results provide mixed support that the manipulations were successful in this study. The means and standard deviations are displayed in Table 1.

Table 1. Means and Standard Deviations by Scenario Conditions for Unexpectedness of Behavior, Importance of Behavior and Valence of Behavior

\begin{tabular}{ccccccc}
\hline & \multicolumn{2}{c}{ Unexpectedness } & \multicolumn{2}{c}{ Importance } & \multicolumn{2}{c}{ Valence } \\
$\begin{array}{l}\text { Scenario Conditions } \\
\text { The Secret }\end{array}$ & $\mathrm{M}$ & $\mathrm{SD}$ & $\mathrm{M}$ & $\mathrm{SD}$ & $\mathrm{M}$ & $\mathrm{SD}_{-}$ \\
Positive & 4.10 & 1.13 & 3.54 & 1.51 & 4.82 & .65 \\
Negative & 5.10 & 1.27 & 5.00 & 1.45 & 3.23 & .75 \\
& & & & & & \\
The Party & 4.00 & 1.27 & 4.10 & 1.36 & 4.96 & .54 \\
Positive & 5.91 & .85 & 5.57 & 1.51 & 3.50 & .77 \\
Negative & & & & & & \\
\hline
\end{tabular}

Both of the negatively valenced scenarios (i.e., negative secret and negative party) were perceived as negative expectancy violations based on their unexpectedness scores $(M=5.10$ and 5.91 respectively). Conversely, neither of the two positively valenced scenarios (i.e., positive party and positive secret) were perceived as positive expectancy violations based on their unexpectedness scores $(M=4.10$ and $M=4.00)$. Pairwise comparisons indicate no significant within-scenario differences (e.g., positive party vs. positive secret) on unexpectedness of behavior, but did indicate a significant between-scenario difference (i.e., positive vs. negative) in unexpectedness of behavior. Specifically, the negative scenarios were perceived as significantly more unexpected (i.e., expectancy violation) than the positive scenarios (see Table 2).

As for importance/intensity of the behavior, the two negatively valenced scenarios yielded significantly higher scores ( $M=5.00$ and $M=5.57)$ compared to the two positively valenced scenarios $(M=3.55$ and $M=4.10)$. This suggests that overall, the negative scenarios were viewed as having greater importance for the relationship than the positive scenarios. Pairwise comparisons indicate no significant within-scenario differences on importance of behavior, but did indicate a significant between-scenario difference on importance of behavior. Specifically, negative scenarios were perceived as significantly more important and intense for the relationship than the positive scenarios (see Table 2).

Table 2. Pairwise Comparisons by Scenario Conditions for Unexpectedness of Behavior, Importance of Behavior, and Valence of Behavior

\begin{tabular}{|c|c|c|c|c|c|c|}
\hline \multirow[b]{3}{*}{ Scenario Comparison } & \multicolumn{2}{|c|}{ Unexpectedness } & \multicolumn{2}{|c|}{ Importance } & \multicolumn{2}{|c|}{ Valence } \\
\hline & \multicolumn{2}{|c|}{ Mean } & \multicolumn{2}{|c|}{ Mean } & \multicolumn{2}{|c|}{ Mean } \\
\hline & Diff. & S.E. & Diff. & S.E. & Diff. & S.E. \\
\hline Positive Secret w/ & & & & & & \\
\hline Negative Secret & $-1.01 *$ & 0.23 & $-1.45 *$ & 0.29 & $1.58 *$ & 0.14 \\
\hline Positive Party & 0.10 & 0.24 & -0.55 & 0.30 & -0.15 & 0.14 \\
\hline Negative Party & $-1.82 *$ & 0.23 & $-2.03 *$ & 0.30 & $1.31 *$ & 0.14 \\
\hline \multicolumn{7}{|l|}{ Negative Secret w/ } \\
\hline Positive Secret & $1.01 *$ & 0.23 & $1.45 *$ & 0.29 & $-1.58 *$ & 0.14 \\
\hline Positive Party & $1.10^{*}$ & 0.24 & $0.91 *$ & 0.31 & $-1.73 *$ & 0.14 \\
\hline Negative Party & $-0.81 *$ & 0.23 & -0.57 & 0.30 & -0.27 & 0.14 \\
\hline \multicolumn{7}{|l|}{ Positive Party w/ } \\
\hline Positive Secret & -0.10 & 0.24 & 0.55 & 0.30 & 0.15 & 0.14 \\
\hline Negative Secret & $-1.10 *$ & 0.24 & $-0.91 *$ & 0.31 & $1.73 *$ & 0.14 \\
\hline Negative Party & $-1.91 *$ & 0.24 & $-1.48 *$ & 0.31 & $1.46^{*}$ & 0.15 \\
\hline \multicolumn{7}{|l|}{ Negative Party w/ } \\
\hline Positive Secret & $1.82 *$ & 0.23 & $2.03 *$ & 0.30 & $-1.31 *$ & 0.14 \\
\hline Negative Secret & $0.81 *$ & 0.23 & 0.57 & 0.30 & 0.27 & 0.14 \\
\hline Positive Party & $1.91 *$ & 0.24 & $1.48 *$ & 0.31 & $-1.46 *$ & 0.15 \\
\hline
\end{tabular}

$*$ indicates the mean difference is significant at $\mathrm{p}=.05$ level. Significance tests were adjusted for multiple comparisons with the Bonferroni adjustment. 
Lastly, in terms of valence of behaviors, the two negatively valenced scenarios were rated as relatively negative $(M=$ 3.23 and $M=3.50)$ whereas the two positively valenced scenarios were rated as somewhat positive $(M=4.81$ and $M=$ 4.96). Pairwise comparisons indicate no significant within-scenario differences on valence of behaviors, but did indicate a significant between-scenario difference on valence of behaviors. Specifically, the two positive scenarios were rated as significantly more positive than the two negative scenarios (see Table 2).

Given that there were no significant within-scenario differences in terms of participants' ratings on unexpectedness, importance, and valence of behavior, the two positive scenarios will be collapsed into one group (i.e., pro-relationship behaviors) whereas the two negative scenarios will be collapsed into a second group (i.e., negative expectancy violations).

\subsection{Test of the Hypotheses}

Due to the nature of the hypotheses, select cases of the data set were used in the analyses depending on whether the focus was on examining pro-relationship behaviors or negative expectancy violations. Multiple regressions were used to test each of the hypotheses with intimacy and commitment levels as predictors. Each hypothesis will now be addressed.

\subsubsection{Hypothesis One}

$\mathrm{H} 1$ predicted that the level of perceived commitment/intimacy will be negatively related to the level of unexpectedness for those in the positive behavior conditions. A multiple regression model was examined with unexpectedness of behavior regressed onto commitment and intimacy for those in the positive behavior conditions. The overall model was significant, $R^{2}=.46$, adjusted $R^{2}=.45, F(2,91)=38.89, p<.001$. Results indicate a significant effect of commitment, $\beta$ $=-.41, t(91)=-3.99, p<.001$, and intimacy, $\beta=-.34, t(91)=-3.32, p<.05$ on unexpectedness of behavior. Specifically, the more committed/intimate participants perceived their relationships, the less unexpected were pro-relationship behaviors. Hence, H1 was supported.

\subsubsection{Hypothesis Two}

$\mathrm{H} 2$ predicted that the level of perceived commitment/intimacy will be negatively related to the level of importance of behavior within the positive behavior conditions. A multiple regression model was examined with importance of behavior regressed onto commitment and intimacy for those in the positive behavior conditions. The overall model was significant, $R^{2}=.24$, adjusted $R^{2}=.22, F(2,91)=38.89, p<.001$. Results indicate a significant effect of commitment, $\beta$ $=-.29, t(91)=-2.40, p<.05$, and a marginally significant effect of intimacy, $\beta=-.24, t(91)=-1.99, p=.05$ on importance of behavior. Specifically, the more committed/intimate participants perceived their relationships, the less important or intense they perceived pro-relationship behaviors. Hence, $\mathrm{H} 2$ was supported.

\subsubsection{Hypothesis Three}

$\mathrm{H} 3$ predicted that the level of perceived commitment/intimacy will be negatively related to the level of explicitness in response reported within the positive behavior conditions. A multiple regression model was examined with explicitness of response regressed onto commitment and intimacy for those in the positive behavior conditions. The overall model was significant, $R^{2}=.29$, adjusted $R^{2}=.27, F(2,91)=18.32, p<.001$. Results indicate a significant effect of commitment, $\beta=-.27, t(91)=-2.29, p<.05$, and intimacy, $\beta=-.32, t(91)=-2.73, p<.05$ on explicitness of response. Specifically, the more committed/intimate participants perceived their relationships, the less explicit they perceived their response would be to the enactment of pro-relationship behaviors by their partner. Hence, H3 was supported.

\subsubsection{Hypothesis Four}

$\mathrm{H} 4$ predicted that the level of perceived commitment/intimacy will be positively related to the level of importance/severity perceived for negative expectancy violations. A multiple regression model was examined with importance of behavior regressed onto commitment and intimacy for those in the negative expectancy violation conditions. The overall model was significant, $R^{2}=.59$, adjusted $R^{2}=.59, F(2,93)=68.04, p<.001$. Results indicate a significant effect of commitment, $\beta=.49, t(93)=5.32, p<.001$, and intimacy, $\beta=.35$,

$t(93)=3.80, p<.001$ on importance of behavior. Specifically, the more committed/intimate participants perceived their relationships, the more important/severe they perceived the negative expectancy violation to be for the relationship. Hence, $\mathrm{H} 4$ was supported.

\subsubsection{Hypothesis Five}

H5 predicted that the level of perceived commitment/intimacy will be positively related to the level of unexpectedness perceived for negative expectancy violations.

A multiple regression model was examined with unexpectedness of behavior regressed onto commitment and intimacy for those in the negative expectancy violation conditions. The overall model was significant, $R^{2}=.38$, adjusted $R^{2}=.37$, 
$F(2,93)=28.61, p<.001$. Results indicate a significant effect of commitment, $\beta=.33, t(93)=2.87, p<.05$, and intimacy, $\beta=.35, t(93)=3.06, p<.05$ on unexpectedness of behavior. Specifically, the more committed/intimate participants perceived their relationships, the more unexpected they perceived the negative expectancy violation to be for the relationship. Hence, H5 was supported.

\subsubsection{Hypothesis Six}

H6 predicted that the level of perceived commitment/intimacy will be positively related to the level of explicitness reported in discussing negative expectancy violations. A multiple regression model was examined with explicitness of response regressed onto commitment and intimacy for those in the negative expectancy violation conditions. The overall model was significant, $R^{2}=.36$, adjusted $R^{2}=.35, F(2,93)=26.53, p<.001$. Results indicate a significant effect of commitment, $\beta=.26, t(93)=2.28, p<.05$, and intimacy, $\beta=.39$,

$t(93)=3.42, p<.05$ on explicitness of response. Specifically, the more committed/intimate participants perceived their relationships, the more explicit they perceived their response to be to a negative expectancy violation enacted in their relationship. Hence, H6 was supported.

\subsubsection{Hypothesis Seven}

$\mathrm{H} 7$ predicted that the level of perceived commitment/intimacy will be negatively related to the level of negativity reported in response to negative expectancy violations. A multiple regression model was examined with negativity of response regressed onto commitment and intimacy for those in the negative expectancy violation conditions. The overall model was significant, $R^{2}=.59$, adjusted $R^{2}=.58, F(2,93)=67.47, p<.001$. Results indicate a significant effect of commitment, $\beta=-.35, t(93)=-3.84, p<.001$, and intimacy, $\beta=-.48, t(93)=-5.25, p<.001$ on negativity of response. Specifically, the more committed/intimate participants perceived their relationships, the less negative they perceived their response to be to a negative expectancy violation enacted in their relationship. Hence, $\mathrm{H} 7$ was supported.

\section{Discussion}

Past scholarship on expectancy violations within interpersonal settings largely focused on situations involving only negative expectancy violations, with less attention on responses to positive expectancy violations. Additionally, there is also a gap in our understanding of the effects of relational characteristics on people's perception of and responses to expectancy violating or confirming situations within their personal relationships. The current study addresses both of these shortcomings. Overall, the results indicate that people's perceptions and responses to interpersonal expectancy violations depends to a large extent on their perceived level of commitment and intimacy felt toward their relational partner.

\subsection{Importance of Behaviors}

With respect to participants' perceptions of the importance or intensity of positive and negative behaviors enacted by their relational partner, the results show that the perceptions vary as a function of commitment/intimacy levels between the participant and his/her partner. It was found that for situations involving positive partner behaviors (i.e., enactment of pro-relationship behaviors), those reporting lower levels of commitment/intimacy tended to perceive the behavior as more important/intense than those reporting higher levels of commitment/intimacy. This is not surprising given that for those in highly committed/intimate relationships, the enactment of pro-relationship behaviors is expected and therefore would not constitute an expectancy violation. On the other hand, those not highly committed to their partners are likely to view such pro-relationship behaviors as more relationally intense as it suggests that the other person wants to move the relationship forward at a rate faster than expected (or desired). And so, such a situation is likely to create greater arousal.

\subsection{Negativity of Response to Expectancy Violations}

The current data suggest that the level of commitment/intimacy between two individuals does affect how negatively partners respond to one another following a negative expectancy violation. Specifically, the results indicate that individuals who are highly committed/intimate toward their dating partner will use less negativity to cope with a negative expectancy violation than those less committed/intimate toward their dating partner. This is an interesting finding because it could be argued that those highly committed/intimate in their relationships should be comfortable in punishing their partners for negatively violating expectancies. However, the present results suggest that this is not the case. A plausible explanation is that despite the higher levels of commitment/intimacy reported, it may be that the relationships being reported on (i.e., dating relationships) are still in the early stages of development. And so, it may be more important at this point for these highly committed/intimate individuals to be positive in their responses in order to preserve the relationship.

On the other hand, based on the face literature, those not highly committed/intimate should be less likely to use negative 
strategies (e.g., threat) to deal with a negative situation. The reason being that using negativity may be face-threatening for both parties involved. However, the current set of results suggests that is not the case. Perhaps whether or not a person is willing to engage in a potentially face-threatening act depends on the severity of the expectancy violation, and the degree to which the violating act is also face-threatening. The two negative expectancy violations used in this study are both face-threatening acts (i.e., both involve disclosures that may be embarrassing for the individual). It may be that in situations where the negative expectancy violation is not a face-threatening behavior, those less committed/intimate toward their partner would respond less negatively.

\subsection{Explicitness of Response to Expectancy Violations}

Examining the data on explicitness and expectancy violations/confirmations, the lower the level of commitment/intimacy perceived within a relationship, the more explicit the response to a positive expectancy violation. However, the reverse pattern occurs in situations involving a negative expectancy violation. In these instances, the higher the level of commitment/intimacy perceived within a relationship, the more explicit the response.

Interestingly, even though highly committed individuals are more likely to discuss the negative expectancy violation situation with the other person than their less committed counterparts, they are less willing to use negativity in such discussions. On the other hand, even though less committed/intimate individuals may be more reluctant to say something explicitly to the other person about the negative expectancy violation, they are more negative when they do say something.

\subsection{Limitations and Directions for Future Research}

The study had two limitations worth considering when interpreting the results. First, the use of scenarios depicting positive and negative expectancy violating behaviors may not elicit as intense a response from participants compared to situations involving actual expectancy violations committed by their relational partner. Given that significant results were found, it can be argued that in situations involving real life expectancy violations by the participants' partner, both perceptions and responses to the violations could be amplified. Alternatively, it may be that participants' responses to the situations reflect more of what they would like to do as opposed to what they would actually do when faced with an expectancy violation. Nevertheless, the results of this study do provide some insights into how people may react to interpersonal expectancy violations in situations involving partners they are highly or lowly committed to and intimate with in their relationship. Future studies may benefit on asking participants to report on their perceptions and reactions to an actual relational event involving their relational partner committing a positive/negative expectancy violation.

Additionally, the present study is limited in that only the violated individuals' perceptions and responses were assessed. Lacking are data on the violators' perceptions of and responses to the expectancy violating event. Specifically, when an expectancy violation occurs, it is likely that the event affects both the violators' and the violated individuals' responses to the situation. Aune, Metts, and Hubbard (1998) asserted that in situations involving the discovery of interpersonal deception by one's partner (i.e., a negative expectancy violation), the coping strategies employed by the deceiver varies as a function of the perceived severity of the lie, and its impact on the relationship. The more severe the deception, the more complex the coping strategies need in dealing with the situation (Aune et al., 1998). Moreover, the deceiver will also choose their response to the situation carefully based on how they perceive of event valence (i.e., do they see the deception as a positive/negative behavior). The degree to which the event is perceived positively or negatively directly impacts the message selection process as well (Aune et al., 1998). Future research may therefore benefit from studying how commitment/intimacy level between relational partners likely affect the violators' perceptions of and responses to positive and negative expectancy violations as well.

In closing, the current study adds to the existing body of relational literature regarding positive and negative expectancy violations as perceived through the lenses of relational commitment and intimacy. Future research in this realm may benefit from consideration of emotional arousal associated with such violations. It may be that perceptions and responses differ based on the specific emotion(s) experienced following positive/negative expectancy violations. That is, the appraisal and evaluation process related to an expectancy violation is mediated by emotional response.

\section{References}

Adams, J. M., \& Jones, W. H. (1997). The conceptualization of marital commitment: An integrative analysis. Journal of Personality and Social Psychology, 72, 1177-1196. https://doi.org/10.1037/0022-3514.72.5.1177

Afifi, W. A., \& Faulkner, S. L. (2000). On being "just friends": The frequency and impact of sexual activity in cross-sex friendships. Journal of Social and Personal Relationships, 17, 205-222. https://doi.org/10.1177/0265407500172003

Afifi, W. A., \& Metts, S. (1998). Characteristics and consequences of expectancy violations in close relationships. Journal of Social and Personal Relationships, 15, 365-392. https://doi.org/10.1177/0265407598153004 
Afifi, W. A., Falato, W. L., \& Weiner, J. L. (2001). Identity concerns following a severe relational transgression: The role of discovery method for the relational outcomes of infidelity. Journal of Social and Personal Relationships, 18, 291-308. https://doi.org/10.1177/0265407501182007

Arriaga, X. B., \& Agnew, C. R. (2001). Being committed: Affective, cognitive, and conative components of relationship commitment. Personality and Social Psychology Bulletin, 27, 1190-1203. https://doi.org/10.1177/0146167201279011

Aune, R. K., Metts, S., \& Hubbard, A. E. (1998). Managing the outcomes of discovered deception. Journal of Social Psychology, 138 (6), 677-690. https://doi.org/10.1080/00224549809603254

Bevan, J. L. (2003). Expectancy violations theory and sexual resistance in close, cross-sex relationships. Communication Monographs, 70, 68-82. https://doi.org/10.1080/03637750302476

Burgoon, J. K. (1993). Interpersonal expectations, expectation violations, and emotional communication. Journal of Language and Social Psychology, 12, 30-48. https://doi.org/10.1177/0261927X93121003

Burgoon, J. K., \& Hale, J. L. (1988). Nonverbal expectancy violations theory: Model elaboration and application to immediacy behaviors. Communication Monographs, 55, 58-79. https://doi.org/10.1080/03637758809376158

Emmers, T. M., \& Dindia, K. (1995). The effect of relational stage and intimacy on touch: An extension of Guerrero and Anderson. Personal Relationships, 2, 225-236. https://doi.org/10.1111/j.1475-6811.1995.tb00088.x

Falk, D. R., \& Wagner, P. N. (2001). Intimacy of self-disclosure and response processes as factors affecting the development of interpersonal relationships. The Journal of Social Psychology, 125, 557-570. https://doi.org/10.1080/00224545.1985.9712029

Fehr, B. (1999). Laypeople's conceptions of commitment. Journal of Personality and Social Psychology, 76, 90-103. https://doi.org/10.1037/0022-3514.76.1.90

Guerrero, L. K. (1996). Attachment-style differences I intimacy and involvement: A test of the four-category model. Communication Monographs, 63, 269-292. https://doi.org/10.1080/03637759609376395

Honeycutt, J. M., Cantrill, J. G., Kelly, P., \& Lambkin, D. (1998). How do I love thee? Let me consider my options: Cognition, verbal strategies, and the escalation of intimacy. Human Communication Research, 25, 39-63. https://doi.org/10.1111/j.1468-2958.1998.tb00436.x

Impett, E. A., Beals, K. P., \& Peplau, L. A. (2001). Testing the investment model of relationship commitment and stability in a longitudinal study of married couples. Current Psychology, 20(4), 312-326.

https://doi.org/10.1007/s12144-001-1014-3

LePoire, B., \& Burgoon, J. K. (1994). Two contrasting explanations of involvement violations: Expectancy violations theory versus discrepancy arousal theory. Human Communication Research, 20, 560-591. https://doi.org/10.1111/j.1468-2958.1994.tb00335.x

Miller, R. S., \& Lefcourt, H. M. (1982). Miller social intimacy scale. In J. Fischer \& K. Corcoran (Eds.). Measures for clinical practice: A sourcebook ( $2^{\text {nd }}$ ed., pp. 359-361). New York: Free Press.

Pilkington, C. J., \& Woods, S. P. (1999). Risk in intimacy as a chronically accessible schema. Journal of Social and Personal Relationships, 16, 249-263. https://doi.org/10.1177/0265407599162007

Prager, K. J. (1995). The psychology of intimacy. New York: Guilford Press.

Roloff, M. E., \& Cloven, D. H. (1994). When partners transgress: Maintaining violated relationships. In D. J. Canary \& L. Stafford (Eds.), Communication and relational maintenance (pp. 23-44). San Diego, CA: Academic Press.

Roloff, M. E., \& Solomon, D. H. (2002). Conditions under which relational commitment leads to expressing or withholding relational complaints. International Journal of Conflict Management, 13(3), 276-291. https://doi.org/10.1108/eb022877

Rusbult, C. E. (1980). Commitment and satisfaction in romantic associations: A test of the investment model, Journal of Experimental Social Psychology, 16, 172-186. https://doi.org/10.1016/0022-1031(80)90007-4

Rusbult, C. E. (1983). A longitudinal test of the investment model: The development and deterioration of satisfaction and commitment in heterosexual involvements. Journal of Personality and Social Psychology, 45, 101-117. https://doi.org/10.1037/0022-3514.45.1.101

Rusbult, C. E., \& Buunk, B. P. (1993). Commitment processes in close relationships: An interdependence analysis. Journal of Social and Personal Relationships, 10, 175-204. https://doi.org/10.1177/026540759301000202 
Rusbult, C. E., Drigotas, S. M., \& Verette, J. (1994). The investment model: An interdependence analysis of commitment processes and relationship maintenance phenomena. In D. Canary \& L. Stafford (Eds.), Communication and relational maintenance (pp. 115-139). New York: Academic Press.

Rusbult, C. E., Johnson, D. J., \& Morrow, G. D. (1986). Predicting satisfaction and commitment in adult romantic involvements. Social Psychology Quarterly, 39, 81-89. https://doi.org/10.2307/2786859

Samp, J. A. (2000). Relationship and self-driven influences on goal characteristics for problematic events: Components of a cybernetic cycle. Communication Studies, 51, 329-351. https://doi.org/10.1080/10510970009388530

Samp, J. A., \& Solomon, D. H. (1998). Communicative responses to problematic event in close relationships I: The variety and characteristics of goals. Communication Research, 25, 66-95. https://doi.org/10.1177/009365098025001003

Seki, K., Matsumoto, D., \& Imahori, T. T. (2002). The conceptualization and expression of intimacy in Japan ant the United States. Journal of Cross-Cultural Psychology, 33, 303-319. https://doi.org/10.1177/0022022102033003006

Solomon, D. H. (1997). A developmental model of intimacy and date request explicitness. Communication Monographs, 64, 99-118. https://doi.org/10.1080/03637759709376409

Vangelisti, A. L., \& Crumley, L. P. (1998). Reactions to messages that hurt. The influence of relational contexts. Communication Monographs, 65, 173-196. https://doi.org/10.1080/03637759809376447

Wieselquist, J., Rusbult, C. E., Foster, C. A., \& Agnew, C. R. (1999). Commitment, pro relationship behavior, and trust in close relationships. Journal of Personality and Social Psychology, 77, 942-966.

https://doi.org/10.1037/0022-3514.77.5.942

\section{Appendix A: Description of the Expectancy Violations Situations}

\section{The Secret (Positive)}

Your partner has a deep secret that he/she has never revealed to anyone before. Your partner thought that he/she would never reveal this skeleton to his/her closet. One evening, your partner tells you that he/she has never trusted anyone as much as you before and reveals his/her darkest secret to you.

\section{The Secret (Negative)}

You have a deep secret that you have never revealed to anyone before. Until now, you have never trusted anyone enough to reveal this skeleton in your closet. One evening, your partner tells you his/her darkest secret and asks you to tell yours. You have never trusted anybody this much before so you tell it. The next day at dinner with your partner's family, your partner makes your secret the topic at the dinner table.

\section{The Party (Positive)}

You and your partner are at a party hosted by a mutual friend. While you are away getting drinks, your partner starts to tell the crowd about some of your good qualities that really attracted him/her to you. In fact, some of these things even you hadn't heard before. Just as your partner is waxing eloquent about you, you walk into the room.

\section{The Party (Negative)}

You and your partner are at a party hosted by a mutual friend. While you are way getting drinks, your partner starts to tell the crowd some embarrassing information about you that you really wanted to be kept secret. Just as your partner is sharing the juicy details, you walk into the room.

\section{Copyrights}

Copyright for this article is retained by the author(s), with first publication rights granted to the journal.

This is an open-access article distributed under the terms and conditions of the Creative Commons Attribution license which permits unrestricted use, distribution, and reproduction in any medium, provided the original work is properly cited. 